\title{
When Magnetic Resonance Imaging Cannot be Missed for Evaluation of Pediatric Seizures
}

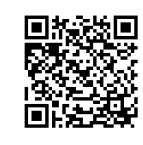

\author{
Tarik Zahouani*, David Valero, Yeh Ling Yiin and Sergey Prokhorov \\ Department of Pediatrics, Lincoln Medical and Mental Health Center, New York
}

Submission: August 24, 2017; Published: September 20, 2018

*Corresponding author: Tarik Zahouani, Department of Pediatrics of Lincoln Medical and Mental Health Center, Bronx, New York,

Email: tarikzahouani@gmail.com

Keywords: Brain tumors, Pediatric, Modality, Slurred speech, Minimal drooling, Epilepsy

Abbreviations: MRI: Magnetic Resonance Imaging; BT: Brain Tumors; ED: Emergency Department; DNET: Dysembryplastic Neuroepithelial

Tumor; CT: Computed Tomography

\section{Introduction}

Brain tumors (BT) account for nearly $25 \%$ of all cancers in children and have the highest mortality rate of all pediatric malignancies [1,2]. Seizure is a common presenting symptom of pediatric brain tumors, but brain tumor remains a rare cause of epilepsy in childhood [3]. Magnetic resonance imaging (MRI) stands as the best diagnostic imaging modality. We present three cases of brain tumors presenting with seizures and diagnosed with MRI.

\section{Case Presentation}

\section{Case 1}

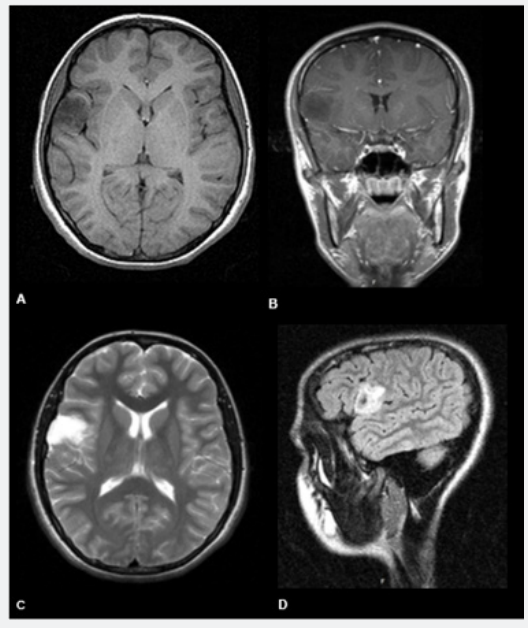

Figure 1: MRI showing a mass within the right frontal operculum, measuring $2.5 \times 2.2 \times 2.0 \mathrm{~cm}$. In the precontrast MRI (left) is hypointense on T1 weighted sequence $(\mathrm{A})$ and hyperintense on the long TR images (C). After contrast (Right) is hypointense in T1 (B) and hyperintense in FLAIR (D).

A 12 y/o female presented an episode of loss of movement of her left hand, associated with asymmetry and twitching of the face, slurred speech, minimal drooling and decrease in strength. Afterwards, the patient lost her consciousness and was found unresponsive with her eyes rolled back. Upon arrival to the emergency department (ED), she was alert, oriented with non-focal neurological examination. She was subsequently admitted and received Levetiracetam 500mg every 12 hours. The electroencephalogram (EEG) showed generalized seizure activity. The MRI revealed a cortical mass in the right frontal operculum likely to be Glioma or Dysembryplastic Neuroepithelial Tumor (DNET) with associated focal cortical dysplasia (Figure 1).

\section{Case 2}

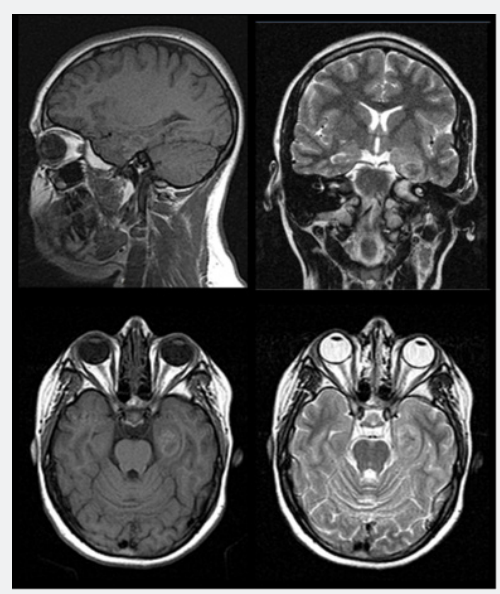

Figure 2: MRI without contrast shows a $1.1 \times 0.8 \times 0.7 \mathrm{~cm}$ mass within the left temporal lobe, hypointense on T1 (left) and T2 (right) with surrounding vasogenic edema.

A $14 \mathrm{y} / \mathrm{o}$ female presented with her first unprovoked seizure. When she awoke, she had stiffness and generalized body movements, with associated tongue and lip biting, but without incontinence. This episode lasted one minute, and after its 
resolution she felt sleepy and drowsy. Physical and neurological examination were unremarkable. She was admitted for further investigation. The EEG showed normal electrical activity. The patient was started on levetiracetam extended release $1000 \mathrm{mg}$ daily and remained seizure free. The MRI showed a mass in the left temporal lobe (Figure 2), hypertrophy of the parahippocampal gyrus and an irregular rim-enhancing mass (Figure 3 ), consisting with neoplasm, toxoplasmosis, neurocysticercosis, tumefactive demyelination, abscess, primary malignancy, or less likely metastatic disease. Patient underwent to neurosurgery for removal of the mass and symptomatically improved with normal follow up neurological exams. The pathology report showed a glioma most consistent with polymorphous low grade neuroepithelial tumor of the young.

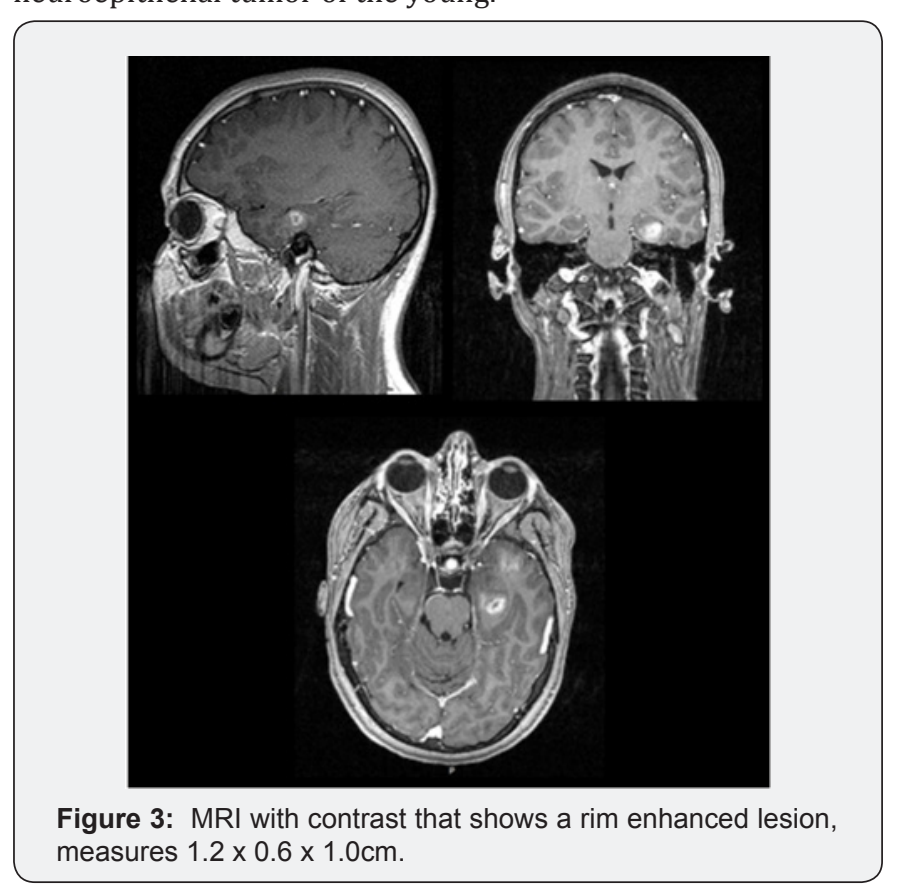

\section{Case 3}

An $18 \mathrm{y} / \mathrm{o}$ male presented to the ED after two seizure episodes. He had multiple episodes of seizures for one year and was non-compliant with Phenytoin treatment. In the ED the patient was alert, active and in no acute distress, with a normal neurological exam. The patient was admitted in the pediatric inpatient unit and received a loading dose of Fosphenytoin and started on a maintenance dose of Valproic acid. During hospital admission the X-ray of his right shoulder showed Hill-Sachs deformity, consistent with prior anterior shoulder dislocations. The MRI revealed a cerebral mass in the right temporal lobe, likely to be neoplasm, neurocysticercosis or encephalomalacia from prior trauma. On the follow up visit, he rejected the surgical approach and elected to follow the lesion.

\section{Discussion}

Seizure is the most common neurologic disorder in childhood and accounts for about $13 \%$ of pediatric brain tumor presentation. The exact relationship between BT and seizures is poorly understood [3]. BT are the deadliest of all pediatric malignancies and their incidence is second only to hematologic malignancies [2]. They are often low-grade lesions such as DNETs, gangliogliomas, and low-grade gliomas. While DNETs and gangliogliomas almost exclusively present with seizures, gliomas may also produce focal neurological deficits secondary to mass effect and cerebral edema. The most common locations for brain tumors causing epilepsy are in the temporal lobe and the perirolandic region [4]. MRI is by far the best diagnostic method to detect brain tumors with a maximum specificity and sensitivity [5].

The availability of high-quality MRI allows for an in vivo view of pathological anatomy as well as detection of lesions such as migration defects and mesial temporal sclerosis, both of which are known causes of childhood onset seizure. These two abnormalities are not readily seen on computed tomography (CT). MRI can also detect brain lesions in patients who had a normal CT [6].

The International League Against Epilepsy recommends neuroimaging with an MRI for all epileptic patients who do not have a definitive identifiable idiopathic epilepsy syndrome [6]. MRI is also recommended for children who develop epilepsy before 2 years of age or in whom seizures continue despite first line drug treatment [7].

The EEG can be useful in suggesting a structural abnormality, especially in children with simple and complex partial seizures; however, the correlation between focal EEG findings and structural lesions is neither close nor consistent [8].

Our patients presented with seizures and EEG did not suggest a structural abnormality, hence the indication to perform MRI which made the diagnosis. This gives us confidence in ordering MRI study even if neurological examination is unrevealing and EEG is normal. Head CT would have been not diagnostic.

\section{Conclusion}

Seizure is a common presentation of brain tumors in children, and is rarely accompanied by focal neurological signs, particularly in older children. Neuroimaging with MRI should be undertaken routinely for epilepsy when seizures had their onset in the first two years after birth, have focal features and when EEG is unrevealing.

\section{References}

1. Klitbo DM, Nielsen R, Illum NO, Wehner PS, Carlsen N (2011) Symptoms and time to diagnosis in children with brain tumours. Dan Med Bull 58(7): A4285.

2. Lanphear J, Sarnaik S (2014) Presenting Symptoms of Pediatric Brain Tumors Diagnosed in the Emergency Department. Pediatr Emerg Care 30(2): 77-80.

3. Fattal-Valevski A, Nissan N, Kramer U, Constantini S (2013) Seizures as the clinical presenting symptom in children with brain tumors. J Child Neurol 28(3): 292-296.

4. Fallah A, Weil AG, Sur S, Miller I, Jayakar P, et al. (2015) Epilepsy 
surgery related to pediatric brain tumors: Miami Children's Hospital experience. J Neurosurg Pediatr 16(6): 675-680.

5. Preuß M, Preiss S, Syrbe S, Nestler U, Fischer L, et al. (2015) Signs and Symptoms of Pediatric Brain Tumors and Diagnostic Value of Preoperative EEG. Childs Nerv Syst 31(11): 2051-2054.

6. Ghofrani M (2013) Approach to the First Unprovoked Seizure- PART I. Iran J Child Neurol 7(3): 1-5.
7. Wilne SH, Ferris RC, Nathwani A, Kennedy CR (2006) The presenting features of brain tumors: A review of 200 cases. Arch Dis Child 91(6): 502-506.

8. Ibrahim K, Appleton R (2004) Seizures as the presenting symptom of brain tumours in children. Seizure 13: 108-112.
This work is licensed under Creative Commons Attribution 4.0 License DOI: 10.19080/JOJCS.2018.08.555743

\section{Your next submission with Juniper Publishers will reach you the below assets}

- Quality Editorial service

- Swift Peer Review

- Reprints availability

- E-prints Service

- Manuscript Podcast for convenient understanding

- Global attainment for your research

- Manuscript accessibility in different formats

( Pdf, E-pub, Full Text, Audio)

- Unceasing customer service

Track the below URL for one-step submission https://juniperpublishers.com/online-submission.php 